\title{
LONG-TERM MONITORING ON THE SAND SPIT MORPHODYNAMICS AT THE TENRYU RIVER MOUTH
}

\author{
Haijiang Liu ${ }^{1}$, Yoshimitsu Tajima ${ }^{1}$ and Shinji Sato ${ }^{1}$
}

\begin{abstract}
In this study, long-term monitoring on the sand spit morphodynamics at the Tenryu River mouth was carried out based on the time series of sand spit profiles extracted from the field camera recorded images between Apr 2007 and Dec 2009. Time stack images were applied to qualitatively characterize the variation of sand spit morphology at the representative longshore location. Primarily analyses were conducted by focusing on the bulk statistical properties of the recorded sand spit profile data. Detailed insight into the evolution process of the sand spit shoreline location was estimated through the Empirical Orthogonal Function (EOF) analysis. Sand spit riverside morphodynamics presents a short-term, but intensive variation pattern and is found to be closely related to the overtopping or flood events. Modification on the sand spit shoreline location shows an asymmetric nearshore process. In the first two years, slow beach accretion accompanying with the eastward longshore sand movement prevailed; whereas, rapid shoreline erosion, together with the westward longshore sand movement, became predominant in the following half year.
\end{abstract}

Keywords: sand spit morphodynamics; image analysis; time stack image; bulk statistical analysis; EOF

\section{INTRODUCTION}

When investigating the sophisticated nearshore process, prediction of sediment transport and evaluation of beach morphology in this area are difficult tasks considering that they undergo complicated interactions and feedback mechanisms between the acting force and system response, which becomes more embarrassed in terms of a long time period coupled with a fairly wide spatial range. Various beach monitoring programs have been deployed to characterize the corresponding nearshore morphological behaviors (Larson et al., 2003; Southgate et al., 2003).

Over the last two decades, it has been extensively proved that the shore-based video technique, such as the ARGUS system, is a powerful and cost-efficient tool to acquire large amounts of real-time nearshore information with high resolutions in time and space (Holman and Stanley, 2007). In general, field cameras are installed at a fairly two-dimensional coastal site with a straight shoreline and shoreparallel bars where morphological change is mainly caused by wave actions (Aarninkhof, 2003). In this study, a long-term field investigation, based on video imagery, was carried out by focusing on the sand spit morphodynamics. Taking into account the present study area, the estuarine morphology process is rather dynamic and complex under the co-actions of daily waves, tidal current and river discharge, as well as the episodic typhoon and flood events. This process occurs along both cross-shore and longshore directions, even on the riverside of the sand spit. By estimating the sand spit area from recorded images, Liu et al. (2008) studied a short-term morphodynamic process of the corresponding area, which included the sand spit collapse and recovery process mainly ascribing to two successive typhoon events in 2007.

In this paper, further analyses based on the sand spit outline extracted from the field recorded image are conducted with respect to the long-term viewpoint. Long-term monitoring is implemented to present the general evolution process of the sand spit morphodynamics, and to discover the mechanism behind it. Discussions are carried out based on the qualitative description and quantitative analysis on the field recorded images. Through this study, evaluation on the temporal and spatial deformation of the sand spit is demonstrated. At the same time, the general morphodynamic scenario of the sediment movement feature in the research area is proposed.

\section{STUDY AREA AND REASEARCH APPROACH}

\section{Study Area}

Figure 1 illustrates the target area in this study, the sand spit at the Tenryu River mouth, and the field camera deployment together with the camera recording azimuth indicated using dashed lines. The Tenryu-Enshunada fluvial system is located at the west of Shizuoka Prefecture, Japan. Detailed descriptions on this region can be found in Liu et al. (2007). A highly dynamic sand spit extends from the west side of the river mouth, which shows significant spatiotemporal variation owing to the complex external forces. In order to reveal such sophisticated morphodynamic behavior, field cameras

\footnotetext{
${ }^{1}$ Department of Civil Engineering, The University of Tokyo, 7-3-1 Hongo, Bunkyo-ku, Tokyo, 113-8656, Japan
} 
were installed on both sides of the river mouth since Apr 2007, i.e., Seien camera on the west side and Kaketsuka camera on the east side. Camera set-up, capacity and image recording were described in detail in Liu et al. (2008). In this study, the long-term investigation on the sand spit morphodynamics covers a 2.5-year period, extending from Apr 2007 to Dec 2009. During this period, there were three significant typhoons attacking the corresponding area, i.e., T0704, T0709 and T0918, respectively. Relevant physical characteristics of these three typhoon events are summarized in Table 1. After typhoon T0704, sand spit collapse occurred owing to the intensive river flood. Afterwards, seaside recovery of sand spit underwent by the daily wave actions. Wave overtopping during typhoon T0709 induced the riverside recovery of the collapsed area. Detailed analyses on the nearshore process related to these two events can be found in Liu et al. (2008). In the following time period, the wave climate was relatively calm until the visiting of typhoon T0918, which has a significant wave height more than $10 \mathrm{~m}$. Landward migration of the sand spit was confirmed due to the wave overtopping (Takagawa et al., 2011). During the research period, the significant river discharge only occurred accompanying with typhoon T0704, which offered a large amount of sands to the river mouth nearshore area. For the other two typhoons, the corresponding sediment supplies from the Tenryu River played a minor role with respect to the nearshore morphodynamics.

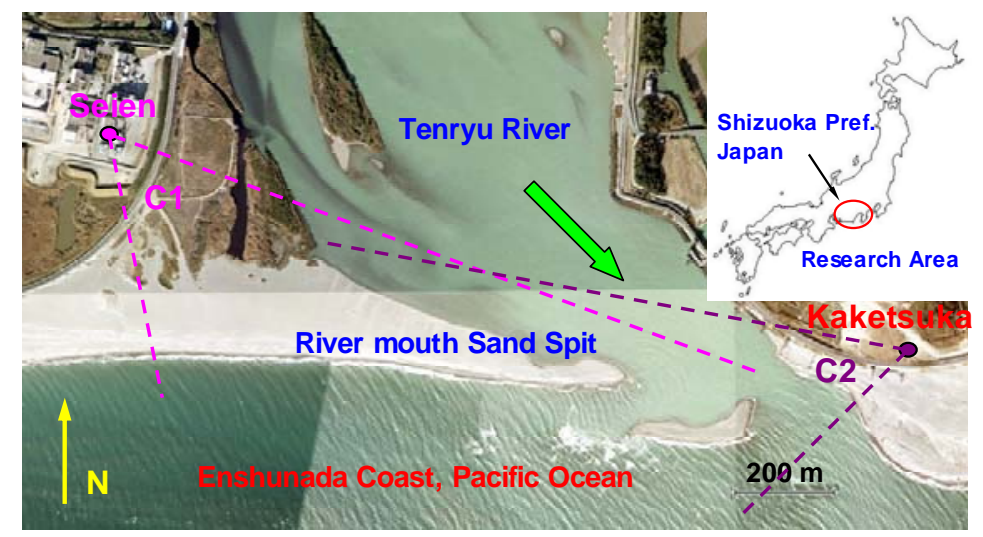

Figure 1. Research area and field camera deployment.

\begin{tabular}{|c|c|c|c|c|c|}
\hline \multicolumn{5}{|c|}{ Table 1. Physical characteristics of three typhoons between Apr 2007 and Dec 2009.} \\
\hline Typhoon & Date & $\begin{array}{c}\text { Significant wave } \\
\text { height } \mathrm{H}_{1 / 3}(\mathrm{~m})\end{array}$ & $\begin{array}{c}\text { Significant wave } \\
\text { period } \mathrm{T}_{1 / 3}(\mathrm{~s})\end{array}$ & $\begin{array}{c}\text { River discharge } \\
\mathrm{Q}\left(\mathrm{m}^{3} / \mathrm{s}\right)\end{array}$ & Memo \\
\hline T0704 & Jul 14, 2007 & 7.1 & 11.2 & 8150 & $\begin{array}{c}\text { Sand spit } \\
\text { collapse } \\
\text { Tand spit } \\
\text { recovery } \\
\text { Landward } \\
\text { migration }\end{array}$ \\
\hline
\end{tabular}

After field image recording, image analysis was performed to extract the useful information for further investigations. The 10 min-averaged time exposure images at zero tide level for each day were selected to remove the individual image noise and to perform the inter-comparison for a long-term period. Acquiring the accurate geo-referencing (the real world location) from the oblique video images is important for the concrete discussion on the nearshore morphodynamics. Based on the image rectification relationship presented by Holland et al. (1997), Liu et al. (2008) introduced the weight function to the ground control points which improves the accuracy of image rectification. By taking into account the simultaneously recorded images from both sides of the river mouth, Figure 2 presents an example of the merged, geo-rectified time exposure image recorded on Jul 9, 2007, which shows clear sand spit characteristics. The spatial resolution of such image is within a few meters in the camera-far field with respect to the sand spit area. In Figure 2, the coordinate system is based on the original point setting at the Seien camera with going eastwardly/southwardly corresponding to the positive longshore/cross-shore positions, respectively. The merged, geo-rectified time exposure images, together with the specified coordinate system, will be employed in this study. 


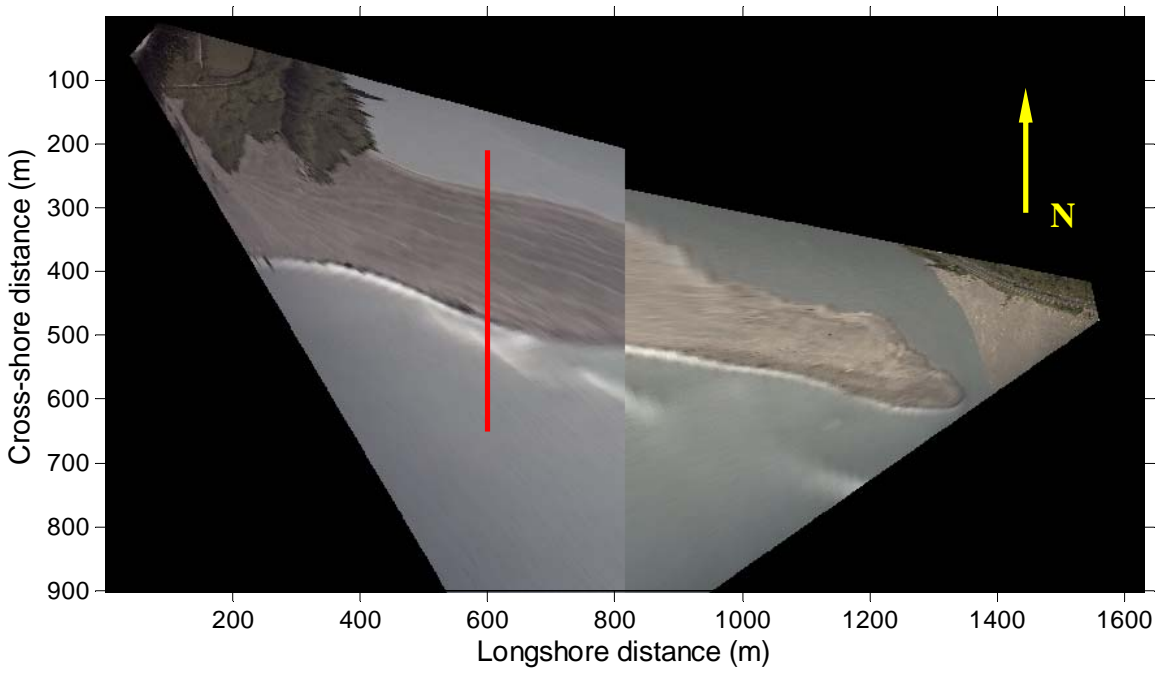

Figure 2. A merged, geo-rectified time exposure image recorded at zero-tide level on Jul 9, 2007.

\section{Methodology}

Time stack images specified at a representative longshore transection position is applied for the qualitative description on the temporal variation of the sand spit configuration. Quantitative analysis is conducted based on the sand spit profiles extracted from the merged, geo-rectified images. Various automated methods have been developed to pick up the shorelines or sand spit profile from images (Plant et al., 2007; Liu et al., 2008). Nevertheless, these approaches tend to be site specific or shortterm applicable and can not routinely apply to the present study area with comparable accuracy to manually extracting the sand spit boundary. Therefore, similar to Fairley et al. (2009), sand spit profiles were obtained manually from images using a graphical user interface. Although a little laborconsuming, this method affords the best accuracy in detecting the sand spit boundary considering the rather hostile field weather conditions during the image recording.

Time exposure images were used which remove boundary discrepancies from individual wave run-up and present a more reliable boundary estimation. Sand spit profiles were only extracted from images with good clarity. To minimize the influence from the wave set-up to the shoreline position, recorded images with a significant wave height larger than $1.1 \mathrm{~m}$ have been excluded from the present analysis. Owing to the episodic camera mechanical problems, image recording failed for one or both cameras sometimes. This makes the sand spit profile extraction impossible for the relevant periods. As a result, temporal spacing of sand spit profile extraction varies from daily to monthly. In total, 354 profiles were picked up between Apr 20, 2007 and Dec 9, 2009.

Preliminary investigation focuses on the simple bulk statistical analysis on the sand spit profile such as the mean, range, standard deviation and correlation coefficient to characterize the nearshore evolution process. Although bulk statistics are quite useful in characterizing long-term beach dynamics, more sophisticated approaches may provide additional insights into how the nearshore responds. In case of sand spit response over large spatial and long temporal scales, Empirical Orthogonal Function (EOF) analysis was applied. EOF analysis, also commonly referred to as Principal Component Analysis (PCA), has become a powerful tool in analyzing the successive coastal survey data sets to reveal the beach profile evolution process and to understand the regularity of the nearshore variability. The application of EOF technique to coastal study starts from the mid 1970s. Pioneer works have been conducted by Winant et al. (1975) to describe the beach profile changes and by Aubrey (1979) to study the seasonal patterns of on/offshore sediment movement. These studies, focusing on the cross-shore variability, relate the first three eigenfunctions to the variation in profile configuration representing the mean beach profile, the seasonal winter bar and summer berm profiles and the low tide terrace. Recently, EOF technique was applied to the assessment on the longshore shoreline variability (Miller and Dean, 2007) and shoreline changes behind the detached breakwaters (Fairley et al., 2009), as well as the variation and prediction of the high-energy shoreline (Hansen and Barnard, 2010).

EOF analysis operates by exploiting the properties of matrices to identify patterns of standing oscillations within a data set which can then be used to represent the data in a more compact form. It reduces the number of data variables required to represent a specified data set. This is achieved by 
linearly decomposing a data set in terms of orthogonal functions both in space and time (Aubery, 1979; Miller and Dean, 2007),

$$
y(x, t)=\sum_{k=1}^{n} y_{k}(x, t)=\sum_{k=1}^{n} a_{k} c_{k}(t) e_{k}(x)
$$

where $y(x, t)$ is the original sand spit profile data recorded at any longshore point $x$ for any time $t$ in which each row contains a series of temporal observations at a specified location and each column includes the spatial observations at a specified time. $y_{k}(x, t)$ is the $k$-th combined eigenfunction pair which consists of the $k$-th spatial eigenfunction, $e_{k}(x)$, and the $k$-th temporal eigenfunction, $c_{k}(t)$. Parameter $n$ is equal to the minimum of $n_{x}$ and $n_{t}$, where $n_{x}$ and $n_{t}$ are the number of spatial and temporal samples respectively. The normalizing factors $a_{k}$ are determined by,

$$
a_{k}=\sqrt{\lambda_{k} n_{x} n_{t}}
$$

in which $\lambda_{k}$ is the eigenvalue associated with the $k$-th eigenfunction. The spatial eigenfunctions, $e_{k}(x)$, are simply the eigenfunctions (eigenvactors) associated with the spatial covariance matrix and can be decided from the equation,

$$
\mathbf{A} e_{k}(x)=\lambda_{k} e_{k}(x)
$$

where the symmetric correlation matrix $\mathbf{A}$ is formed by,

$$
\mathbf{A}=\frac{1}{n_{x} n_{t}}\left(\mathbf{Y} \mathbf{Y}^{T}\right)
$$

in which matrix $\mathbf{Y}$ is made up of the original profile data $y(x, t)$ and $T$ is the matrix transpose operator. Similarly, the temporal eigenfunctions, $c_{k}(t)$, are found by the equations,

$$
\begin{aligned}
& \mathbf{B} c_{k}(t)=\lambda_{k} c_{k}(t) \\
& \mathbf{B}=\frac{1}{n_{x} n_{t}}\left(\mathbf{Y}^{T} \mathbf{Y}\right)
\end{aligned}
$$

The matrices $\mathbf{A}$ and $\mathbf{B}$ have the same non-trivial eigenvalues. The eigenfunction associated with the largest eigenvalue represents the bulk of the variability in the data set, or the data best in a least squares sense; whereas each subsequent eigenfunction accounts for the majority of the remaining variability. Therefore, the original data set can be efficiently represented by a few empirical functions (the lower order modes) which extract the dominant meaningful signals from the background noise described by the higher order modes.

\section{RESULTS AND INTERPRETATIONS}

Taking into account the flied recorded image data set, qualitative description and quantitative analysis on the long-term sand spit morphodynamics are presented in this section. Considering the dominant external forces are different between the seaside and riverside of the sand spit where river flows and daily waves play their roles on two sides' deformation respectively, the whole sand spit morphodynamics is investigated with respect to these two regions.

\section{Qualitative Description}

Qualitative analysis on the sand spit morphodynamics is based on the time stack image to reveal the general variation tendency. Figure 3 presents a time stack image at the $600 \mathrm{~m}$ longshore position as shown in Figure 2 highlighted by a red line. This image covers a period from Apr 20, 2007 to Dec 9, 2009. The dark regions correspond to the days when technical problems occur for image recording or 
there is no zero tide level during the daytime. Considering the riverside, it shows the event-related modification process in Figure 3. Before Jul 2007, there is no significant change on the riverside boundary. During typhoon T0704, the sand spit collapsed at this location due to the river flood which resulted in sudden erosion on the riverside. In the following two months, the recovery process occurred starting from the seaside by the daily normal waves and finally to the riverside as a result from the wave overtopping ascribed to typhoon T0709 (Liu, et al., 2008). In the succedent two years, the sand spit riverside experiences a fairly stable evolution phase since there is no significant river flood or severe overtopping events during this period. On Oct 8, 2009, one powerful typhoon event, T0918, with a significant wave height exceeding $10 \mathrm{~m}$, attacked the river mouth, which migrated the sand spit to the landward direction induced by the sediment movement after the wave overtopping (Takagawa, et al., 2011). In Figure 3, it is confirmed that the riverside boundary shifts riverward remarkably after typhoon T0918. In case of the seaside morphodynamics, different from the riverside, a relatively gradual and long-term variation process is observed in Figure 3. There is no distinct change on the shoreline location after going through typhoons T0704 and T0709. Subsequently, a seasonal migration of the shoreline position is detected. At this location, accretion process occurs during spring and summer (Apr to Sep); whereas, beach erosion (shoreline recession) undergoes in autumn and winter (Sep to Mar).

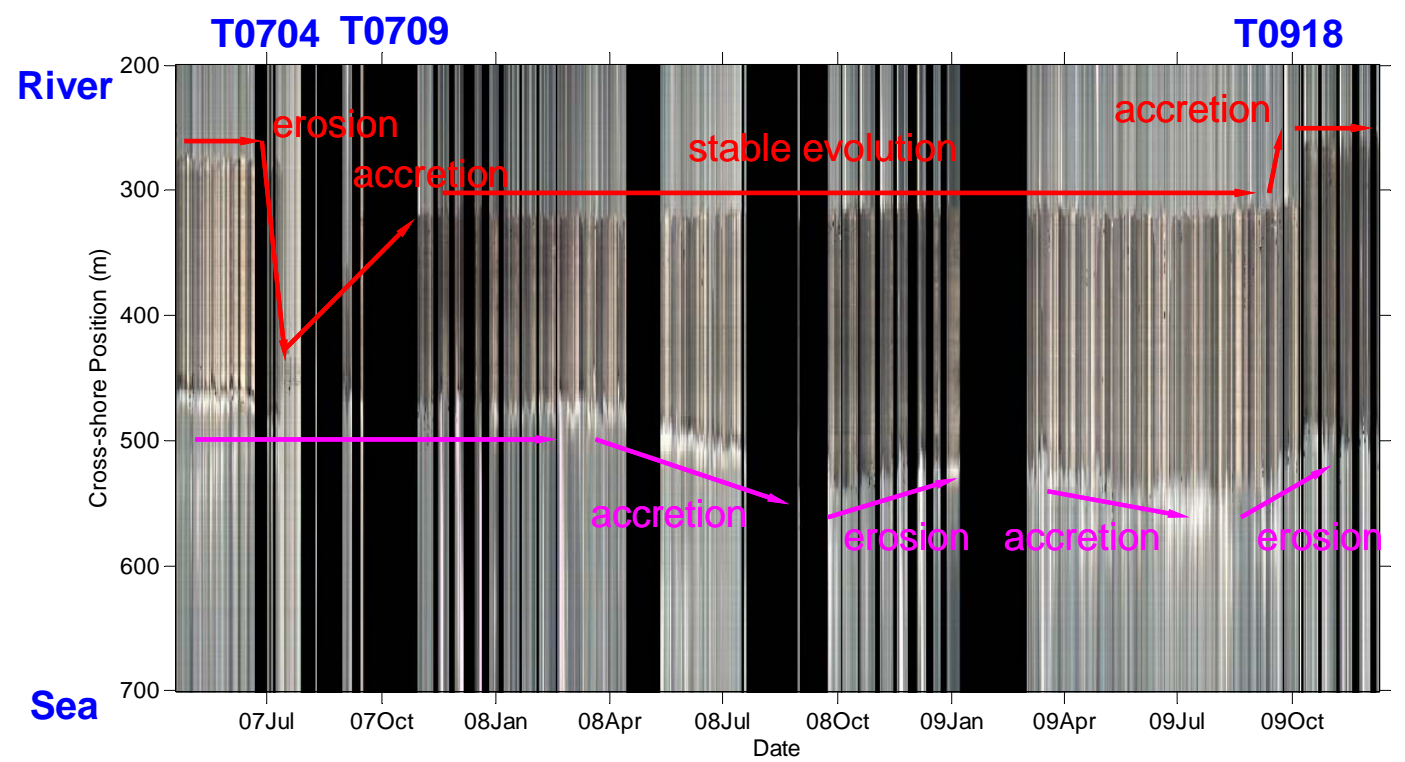

Figure 3. The time stack image at $600 \mathrm{~m}$ longshore position.

\section{Quantitative Analysis}

Attention was firstly paid to the sand spit riverside morphodynamics. Figure 4 shows the temporal variation of riverside boundaries at three representative locations, i.e., $600 \mathrm{~m}, 800 \mathrm{~m}$, and $1000 \mathrm{~m}$, as well as the average location of the sand spit riverside boundary over the longshore range of 450 - 1050 $\mathrm{m}$. Considering that the east part of the sand spit is highly dynamic owing to the multiple external forces, no sand spit exists east of the longshore location $1050 \mathrm{~m}$ at certain times during the image recording period (Liu et al., 2008). Therefore, quantitative analyses were carried out up to the longshore location of $1050 \mathrm{~m}$. In Figure 4, it further confirms that distinct changes on the riverside morphology occur accompanying with the overtopping or flood events. On the other hand, riverside profile modification is rather insignificant under the normal conditions (after T0709 until T0918). Modification on the riverside boundary location is also not spatially uniform mainly ascribed to the different sand spit elevation. Comparing the riverside positions before T0704 and after T0709, about $45 \mathrm{~m}$ erosion happens at $600 \mathrm{~m}$ location. It is about $30 \mathrm{~m}$ at $800 \mathrm{~m}$ location. Further going east at 1000 m location, it is found that erosion caused by typhoon T0704 is fully recovered after typhoon T0709 and there is no clear change on the riverside profile pre and post these two events. After typhoon T0918, landward migration occurred with a magnitude of $65 \mathrm{~m}, 20 \mathrm{~m}$ and $40 \mathrm{~m}$ with respect to these three longshore locations. Further focusing on the temporal variation of the mean riverside profile 
location in Figure 4, it is seen that the distribution of mean position is quite similar to the case of the $800 \mathrm{~m}$ longshore location. Pre-T0704 and post-T0709, the mean riverside suffered $30 \mathrm{~m}$ erosion; whereas, pre-/post-T0918, another $30 \mathrm{~m}$ accretion occurred. In between, the mean position is rather stable at cross-shore location of $350 \mathrm{~m}$. Accordingly, there is no change on the mean riverside position within the present research period, i.e., the $320 \mathrm{~m}$ cross-shore location.

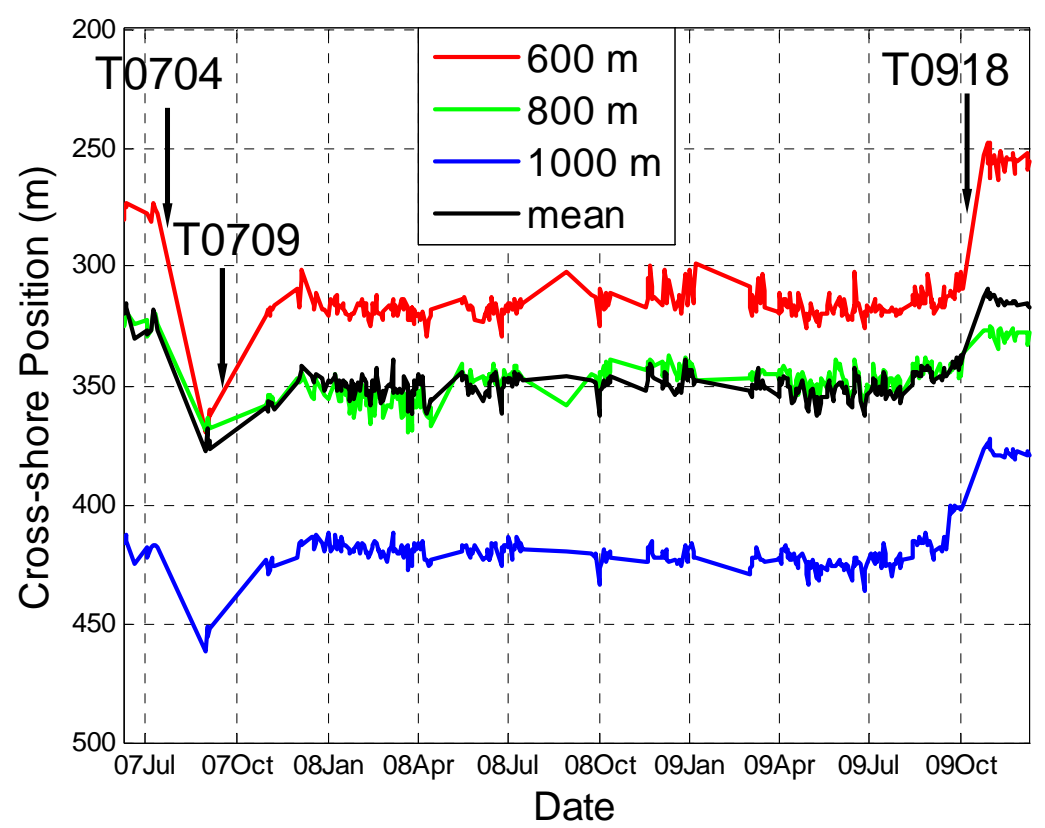

Figure 4. Temporal variation of riverside sand spit boundaries at three specified locations, i.e., $600 \mathrm{~m}, 800 \mathrm{~m}$ and $1000 \mathrm{~m}$, together with the mean position of the sand spit riverside boundary.

Hereafter, interpretations focus on the sand spit seaside morphodynamics by scrutinizing the sand spit shoreline movement during this period. Figure 5 illustrates the bulk statistical analysis results on the time series of shoreline recordings to characterize the shoreline response, which include the mean, range, standard deviation and correlation coefficient over the time period between Jun 2007 - Dec 2009 and longshore range of 300 - 1050 m. In Figure 5(a), the mean shoreline position extends southward from west to east. As indicated by the range, the recorded shoreline position varies by about $\pm 50 \mathrm{~m}$ at most locations, with the smallest bias around $900 \mathrm{~m}$ and the largest excursion at the east end where the spatiotemporal variation of sand spit is sophisticated. Standard deviation of the shoreline position time series is presented in the middle panel of Figure 5. Large standard deviations are observed around 600 $\mathrm{m}$ and at the east end. In which, longshore position of $600 \mathrm{~m}$ corresponds to the sand spit collapse location during typhoon T0704. Although there is no clear difference in terms of the shoreline range shown in Figure 5(a), this location demonstrates a relatively fragile shoreline feature within the research period. Small standard deviation is obtained around $900 \mathrm{~m}$ longshore location which is consistent with the range distribution. Spatial distribution of the correlation coefficient between time series of shoreline locations at specified four longshore locations is presented in Figure 5(c). The maximum correlation (a value of one) is estimated when taking into account the self variation. West of the longshore location of $900 \mathrm{~m}$, there are positive correlations between relevant two locations, e.g., results from $300 \mathrm{~m}, 600 \mathrm{~m}$ and $800 \mathrm{~m}$, which means the shoreline migration in this area accompanies with each other or in the same phase. However, considering the correlation between the west and the east of $900 \mathrm{~m}$, negative correlations are confirmed which illuminates that the shoreline variation is out of phase between these two parts. In other words, shoreline accretion at the west side goes along with shoreline erosion at the east side, or vice versa. This may indicate the nearshore dynamics induced by the longshore sediment transport. 

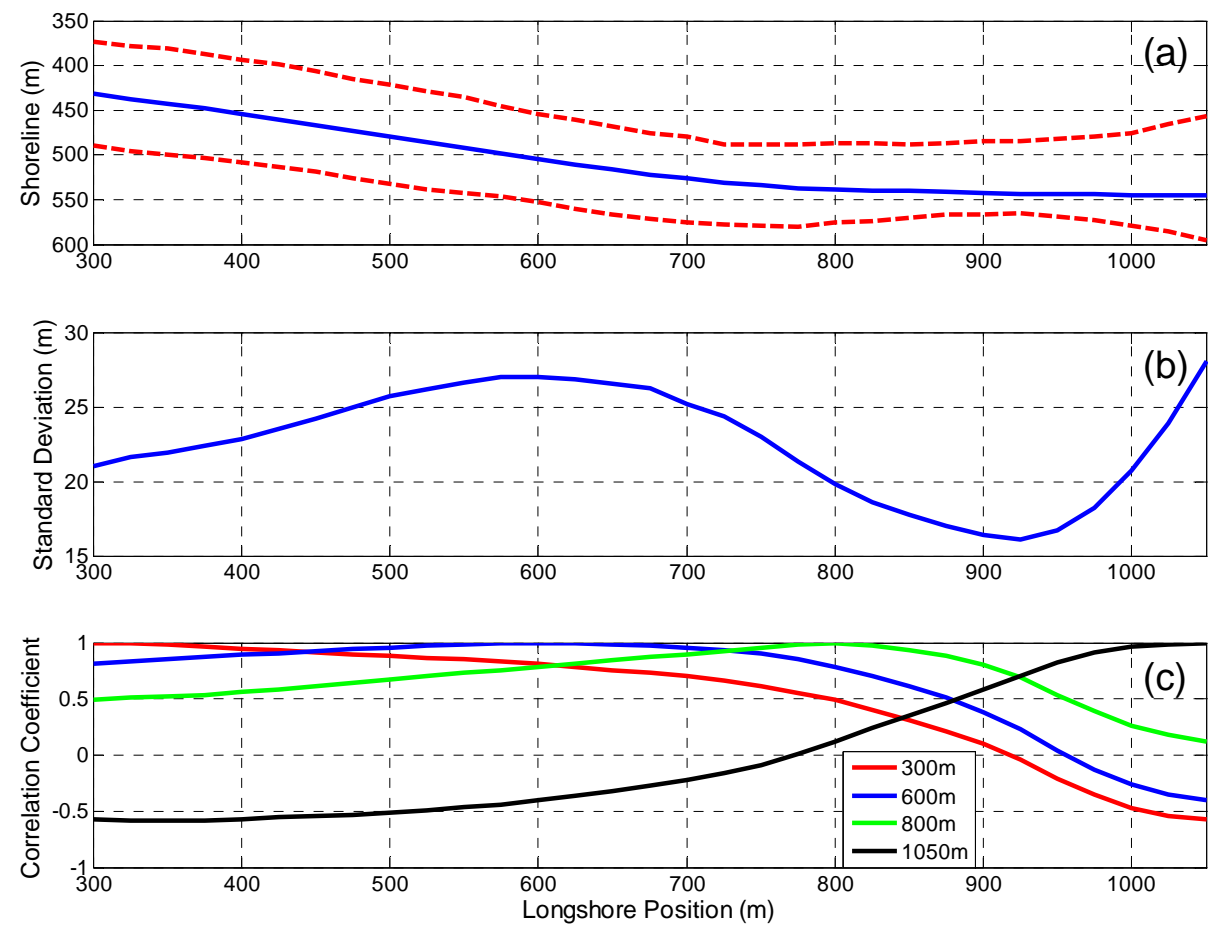

Figure 5. (a) Mean (blue line) and range (red dot line) of the sand spit shoreline data set. (b) Standard deviation of the sand spit shoreline data set. (c) Correlation coefficient between time series of shoreline locations at selected four longshore locations, i.e., $300 \mathrm{~m}, 600 \mathrm{~m}, 800 \mathrm{~m}$ and $1050 \mathrm{~m}$.

To further identify and characterize the sand spit shoreline morphodynamics, EOF analysis was applied to evaluate the dominant modes of variability contained in the shoreline data set. In this study, considering that most of the shoreline variability is represented by the first two modes of the EOF analysis, the first two modes' results will be discussed in detail below.

First mode results are presented in Figure 6, the upper panel shows the spatial eigenfunction $e_{1}(x)$ distribution and the lower panel shows the temporal eigenfunction $c_{1}(t)$ variation. In Figure $6, e_{1}(x)$ exhibits positive values within the whole considered area with gradual increase from west to east. In general, $e_{1}(x)$ displays a strong resemblance to the statistical mean shoreline as shown in Figure 5(a) (being aware that the vertical axis is reversed in Figure 5a). Miller and Dean (2007) referred to $e_{1}(x)$ as the mean shoreline function. Figure 6 demonstrates the shoreline movement indicated from the first spatial eigenfunction is in phase among the entire longshore locations, and is more reflective of the typical shoreline response (advances or retreats) due to the cross-shore processes. Miller and Dean (2007) and Fairley et al. (2009) also linked the first mode variation of the EOF analysis to the crossshore movement. A large $e_{1}(x)$ value at east implicates the cross-shore variation is more significant over there. The first temporal eigenfunction also presents all positive values with a gradual increase from Jun 2007 to Jul 2009 followed by a rapid decrease up to Dec 2009. At the same time, different from the result revealed in the time stack image at $600 \mathrm{~m}$ longshore location (Figure 3), $c_{1}(t)$, which contains the whole sand spit shoreline dynamics, does not present a clear seasonal variation pattern. In order to emphasize the interdependence of the temporal and spatial eigenfunctions, the combined eigenfunction pair for the first mode, $y_{1}(x, t)=a_{1} c_{1}(t) e_{1}(x)$, is demonstrated in Figure 7. Large values correspond to the seaward shoreline positions as illustrated in Figure 2. Figure 7 implicates that within the research period, the sand spit shoreline undergoes a long-term, gradual, but asymmetric modification process with respect to the cross-shore sediment movement. Before Jul 2009, a gradually seaward migration (accretion process) occurs with the $y_{1}(x, t)$ value increased for the first two years; whereas, a rapid landward recession (beach erosion) happened in the following time duration. Such accretion/erosion process is consistent with the variation of the temporal eigenfunction in Figure 6. Nevertheless, there is almost no change on the sand spit mean shoreline location comparing the beginning and ending stages of the present research period, which can be further confirmed from the 
temporal eigenfunction since $c_{1}(t)$ approaches 0.05 at both ends of the target period. This suggests the sand spit went through a cyclic cross-shore movement in these two and half years.
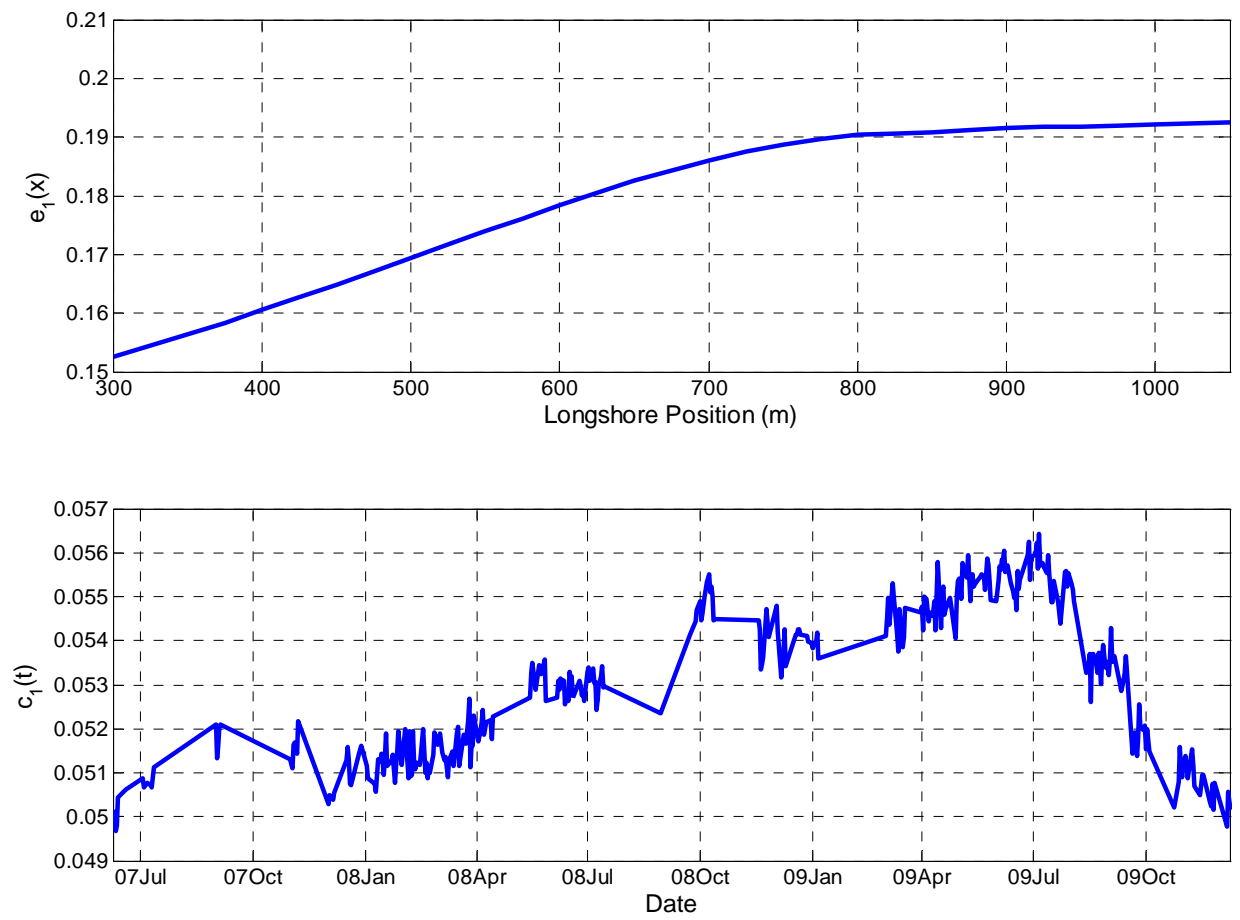

Figure 6. First mode results of the sand spit shoreline variation based on the EOF analysis. Upper panel: spatial eigenfunction, $e_{1}(x)$; Lower panel: temporal eigenfunction, $c_{1}(t)$.

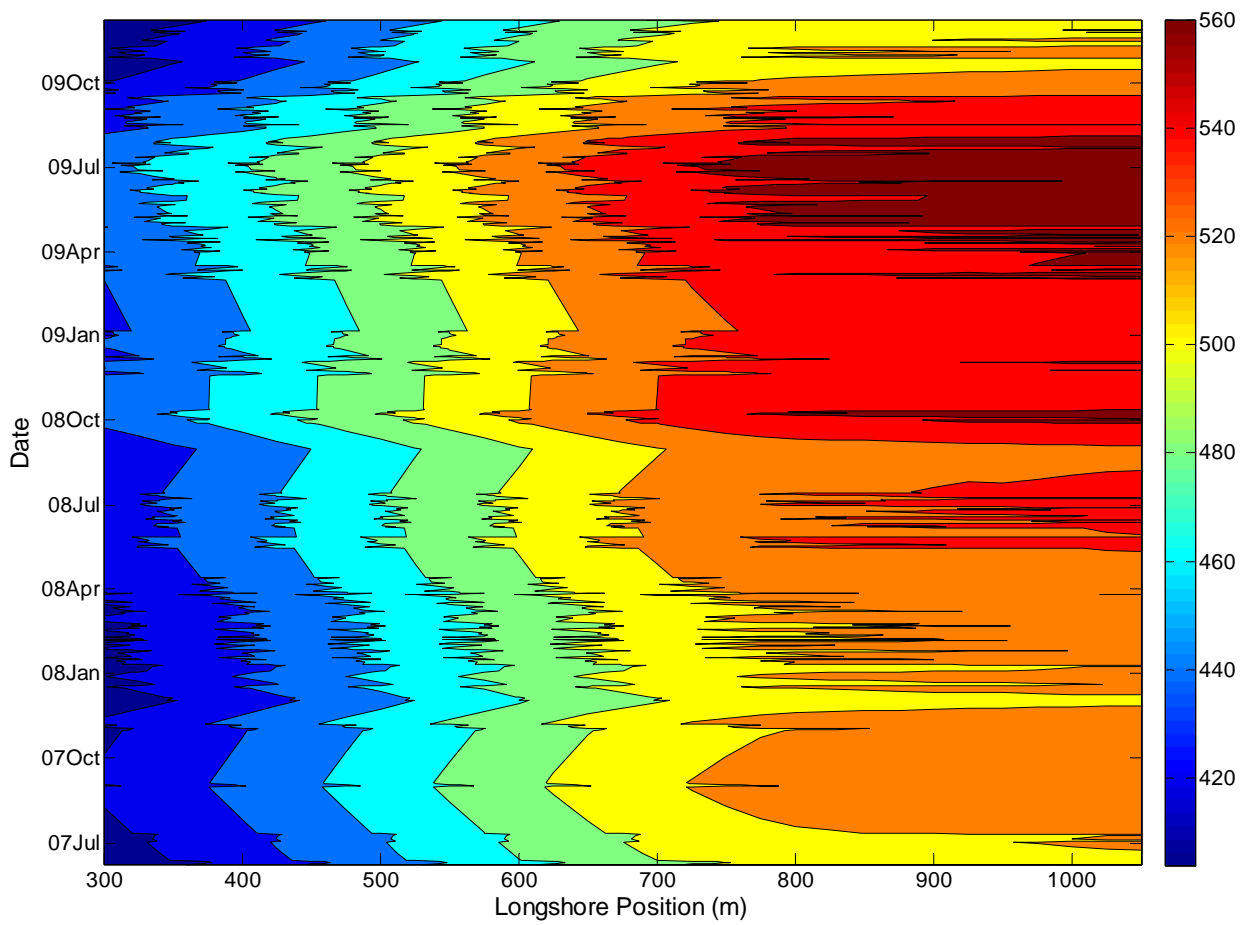

Figure 7. The combined eigenfunction pair, $y_{1}(x, t)$, of the first mode based on the EOF analysis. 
Figure 8 presents the second mode results of the shoreline variation from the EOF analysis. In the upper panel of Figure 8, one nodal point is observed at $775 \mathrm{~m}$ longshore location. Nodal points in spatial eigenfunctions typically separate adjacent areas of erosion and accretion. Therefore, shoreline changes are often referred to as being out of phase across a node (Miller and Dean, 2007). Taking into account the shoreline variability, nodal points are regarded as an indicator of the importance of the longshore sediment processes. Hence, the second mode results generally represent the longshore sand movement. Similar to the result from the spatial distribution of correlation coefficients in Figure 5(c), longshore sediment transport pattern is expected along the sand spit which causes the rotation of shoreline location. Further looking at the temporal eigenfunction of the second mode as shown in the lower panel of Figure 8, $c_{2}(t)$ shows a positive trend through the research period. The temporal eigenfunction changes its sign from negative to positive around Jan 2009, which indicates the change in the longshore transport pattern/direction at that time. On the other hand, regular seasonal variation of $c_{2}(t)$ is still hard to be identified. Figure 9 illustrates the combined eigenfunction pair for the second mode, $y_{2}(x, t)$, after considering the contributions from both $e_{2}(x)$ and $c_{2}(t)$. The longshore transport pattern can be easily identified in Figure 9. It is found before Jan 2009, $y_{2}(x, t)$ presents negative/positive values on the west/east sand spit, which means contribution from the second mode is to transport sands from the west to the east in this period. Such eastward longshore transport feature induces shoreline recession on the west with the simultaneous beach progradation on the east and causes a clockwise rotation of the shoreline centered at the nodal point, i.e., $775 \mathrm{~m}$ longshore location. However, longshore transport changed to the westward direction after Jan 2009. In Figure 9, this is illuminated with positive/negative values on the west/east sand spit, which implicates a westward longshore transport pattern. An anti-clockwise rotation of the shoreline experienced within this period. Such modification on the longshore transport pattern is also confirmed from field surveys. In 2008, sand spit extended significantly to the east, and the sand spit tip was even out of the camera recording range; whereas, it shrunk rapidly to the west after Mar 2009.
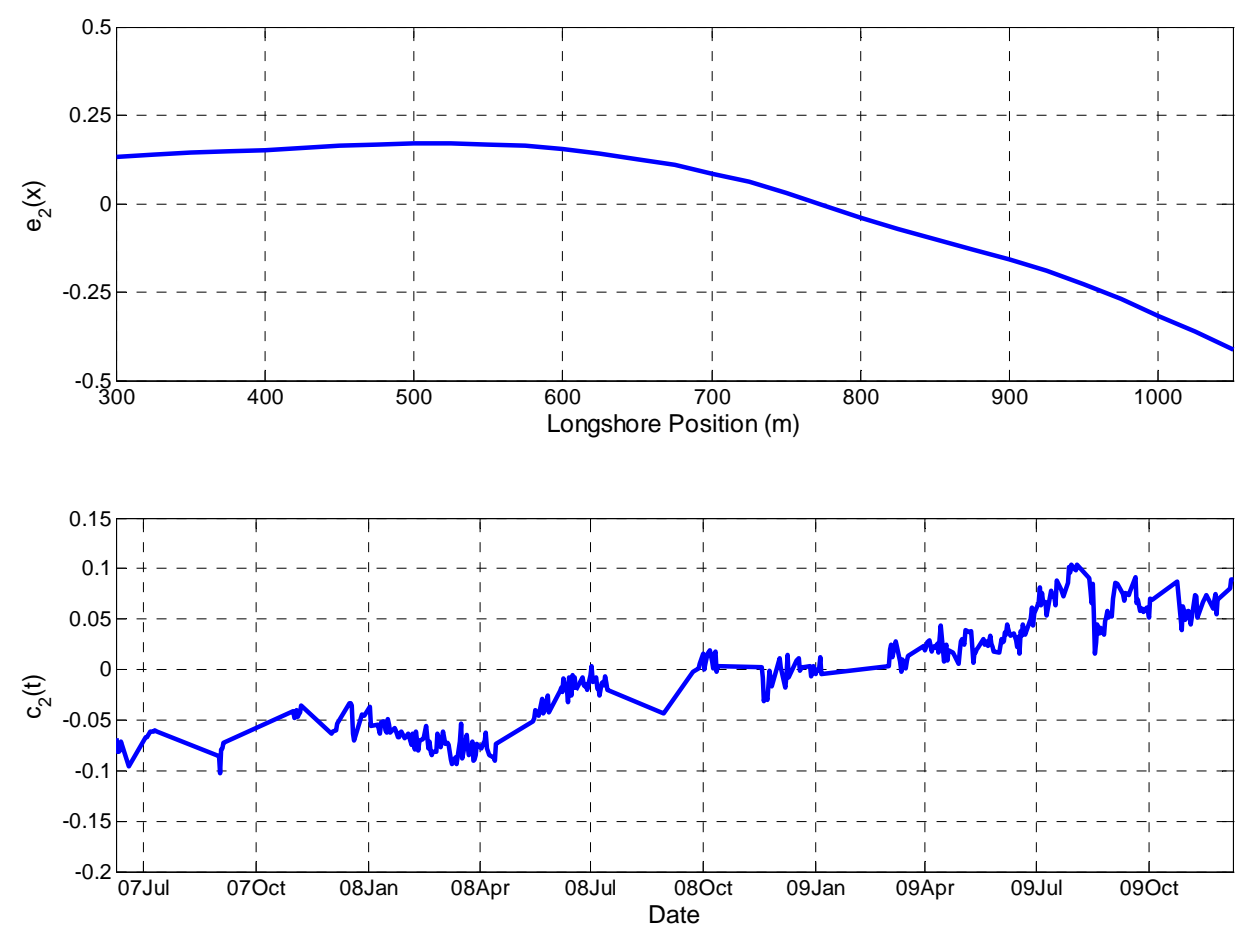

Figure 8. Second mode results of the sand spit shoreline variation based on the EOF analysis. Upper panel: spatial eigenfunction, $\mathrm{e}_{2}(\mathrm{x})$; Lower panel: temporal eigenfunction, $\mathrm{c}_{2}(\mathrm{t})$. 


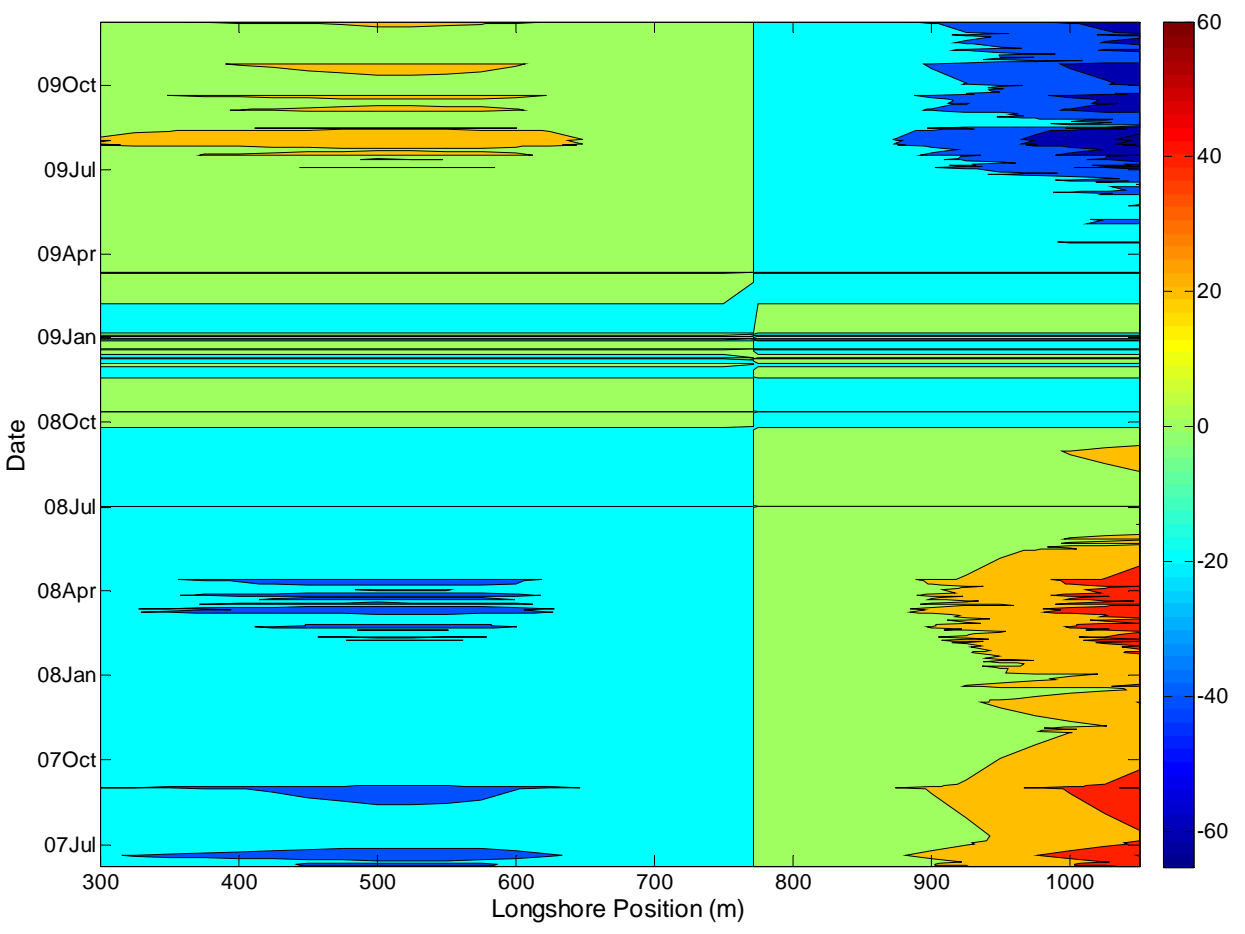

Figure 9. The combined eigenfunction pair, $y_{2}(x, t)$, of the second mode based on the EOF analysis.

After knowing the overall characteristics of the nearshore sand spit morphodynamics, intercomparison among the original shoreline data, the first mode results and the first plus second mode results derived from the EOF analysis was performed at three representative locations, i.e., $500 \mathrm{~m}$ (the west region point), $775 \mathrm{~m}$ (the central point) and $1000 \mathrm{~m}$ (the east region point). The results are presented in Figure 10. Taking into account the first two modes, the EOF analyzing results can reproduce the original shoreline variation satisfactorily since they represent the dominant shoreline variability. As for the first mode results (red lines in Figure 10), it is found that at these three locations, shoreline data gradually increase by a magnitude of 60 m between Jun 2007 and Jul 2009 . Subsequently, rapid reduction of the first mode results is observed. This corresponds to the accretion/erosion processes along the cross-shore direction specified by the EOF analysis as indicated in Figures 6 and 7. Considering the contribution from the second mode results by comparing the red and green lines in Figure 10, sediment longshore transport pattern can be characterized. First, paying attention to the $775 \mathrm{~m}$ longshore location which is the nodal point specified by the second spatial eigenfunction, $e_{2}(x)$, in Figure 8, there is no visible difference between the first mode and the first plus second mode results in Figure 10(b). This is ascribed to the fact that this location is a pivot point and shows stability in terms of the longshore movement. Therefore, contribution from the second mode EOF analysis is rather insignificant. The fist mode result, or the cross-shore movement, is predominant at this location. The small difference between the original data and the first plus second mode results implicates the shoreline variability contributed from the higher order modes of the EOF analysis, e.g., the third mode contribution which will be further discussed in the following context. On the other hand, it is found that in the west region (500 m longshore location) and before Jan 2009, the second mode contributes the shoreline to the landward direction (red line to green line as shown in Figure 10a). Nevertheless, during the same time period, the second mode moves the shoreline to the seaward direction in the east region (1000 m longshore location as shown in Figure 10c). This indicates the nearshore sediment is transported from the west to the east in this period. After Jan 2009, an opposite scenario occurred. The second mode contributes shoreline to the seaward/landward direction in the west/east region, which corresponds to a westward longshore transport feature. Such longshore sediment movement pattern is in agreement with the interpretation on the longshore variability revealed in Figures 8 and 9. 

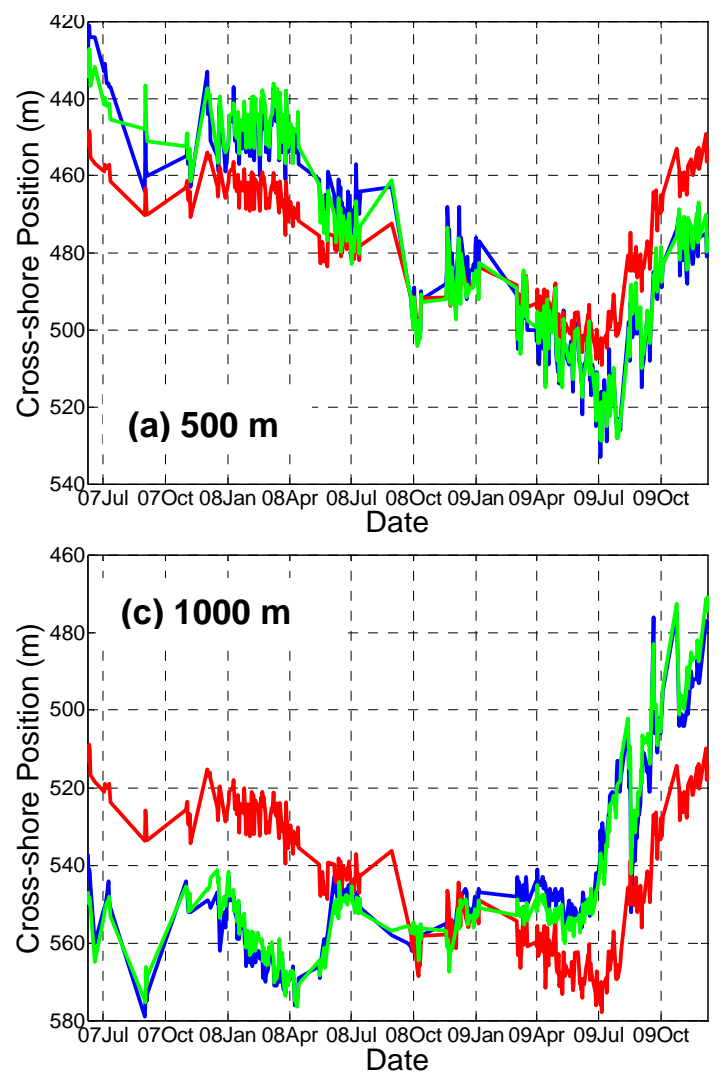

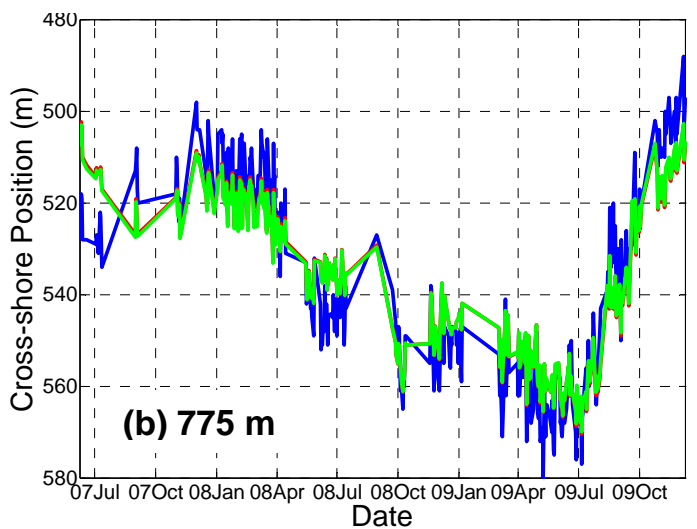

Date

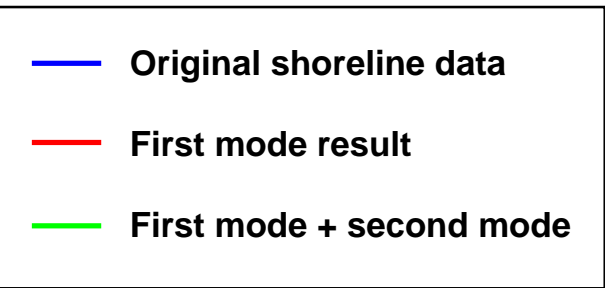

Figure 10. Inter-comparison among the original shoreline data, the first mode results and the first plus second mode results derived from the EOF analysis at three representative longshore locations, i.e., $500 \mathrm{~m}$, $775 \mathrm{~m}$ and $1000 \mathrm{~m}$.

Modes higher than the second explain an increasingly small amount of the shoreline variance and generally show increasing longshore variability in various shoreline topographic features. Figure 11 illustrates the sand spit shoreline variability contributed from the third mode of the EOF analysis. There are two nodal points existing along the sand spit shoreline with respect to the third spatial eigenfunction, $e_{3}(x)$, one at $540 \mathrm{~m}$ longshore location and the other at $895 \mathrm{~m}$ longshore location. This implicates a more complex longshore transport feature than that revealed from the second spatial eigenfunction which has only one nodal point as shown in the upper panel of Figure 8. Result of the third temporal eigenfunction, $c_{3}(t)$, is shown in the lower panel of Figure 11. Influence from typhoon events can be identified through the $c_{3}(t)$ distribution. After typhoons T0704 and T0709, $c_{3}(t)$ suddenly changes its value from -0.13 to 0.02 , which means the longshore transport pattern indicated from the third mode changed its direction pre and post these typhoons. This can also be recognized from the third combined eigenfunction pair distribution, $y_{3}(x, t)$, as shown in Figure 12. Before typhoons, the third mode longshore transport moved sands from the middle to both the west and the east, a divergent process from the middle; whereas, after typhoons, the longshore transport moved sands from two ends to the middle, a convergent process to the middle. After typhoon T0918 on Oct 8, 2009, there is also a rapid increase on $c_{3}(t)$ values which modifies the previous decreasing trend of the temporal eigenfunction. Besides the effect from the typhoon events, the general long-term process can also be confirmed from the $c_{3}(t)$ distribution. After typhoon T0709, a slowly decreasing trend prevailed until May 2009 with a zero-crossing point around Jul 2008. In Figure 12, this process is represented by a convergent pattern between Oct 2007 and Jul 2008 and the divergent pattern between Jul 2008 and May 2009. Nevertheless, between May and Aug 2009, a rapid increasing trend on $c_{3}(t)$ is observed with a zero-crossing point around Jul 2009 which changed the longshore movement to the convergent pattern again as demonstrated in Figure 12. After Aug 2009, $c_{3}(t)$ presents a decreasing trend. However, this process was interrupted and modified by typhoon T0918 as mentioned previously. Comparing the shoreline variation amplitude in Figures 9 and 12, it is further verified that the contribution to the shoreline variability from the third mode plays a minor role than the second mode. 

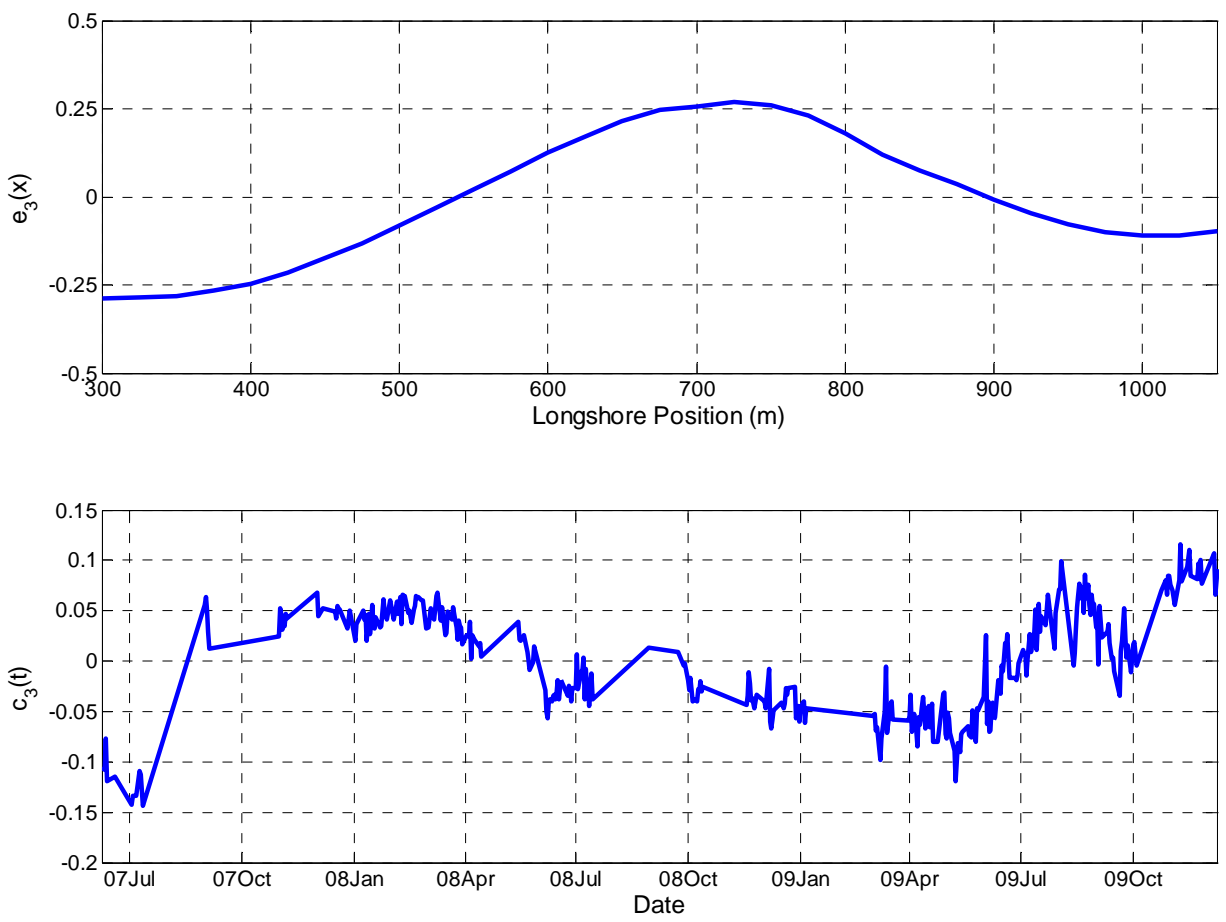

Figure 11. Third mode results of the sand spit shoreline variation based on the EOF analysis. Upper panel: spatial eigenfunction, $\mathrm{e}_{3}(\mathrm{x})$; Lower panel: temporal eigenfunction, $\mathrm{c}_{3}(\mathrm{t})$.

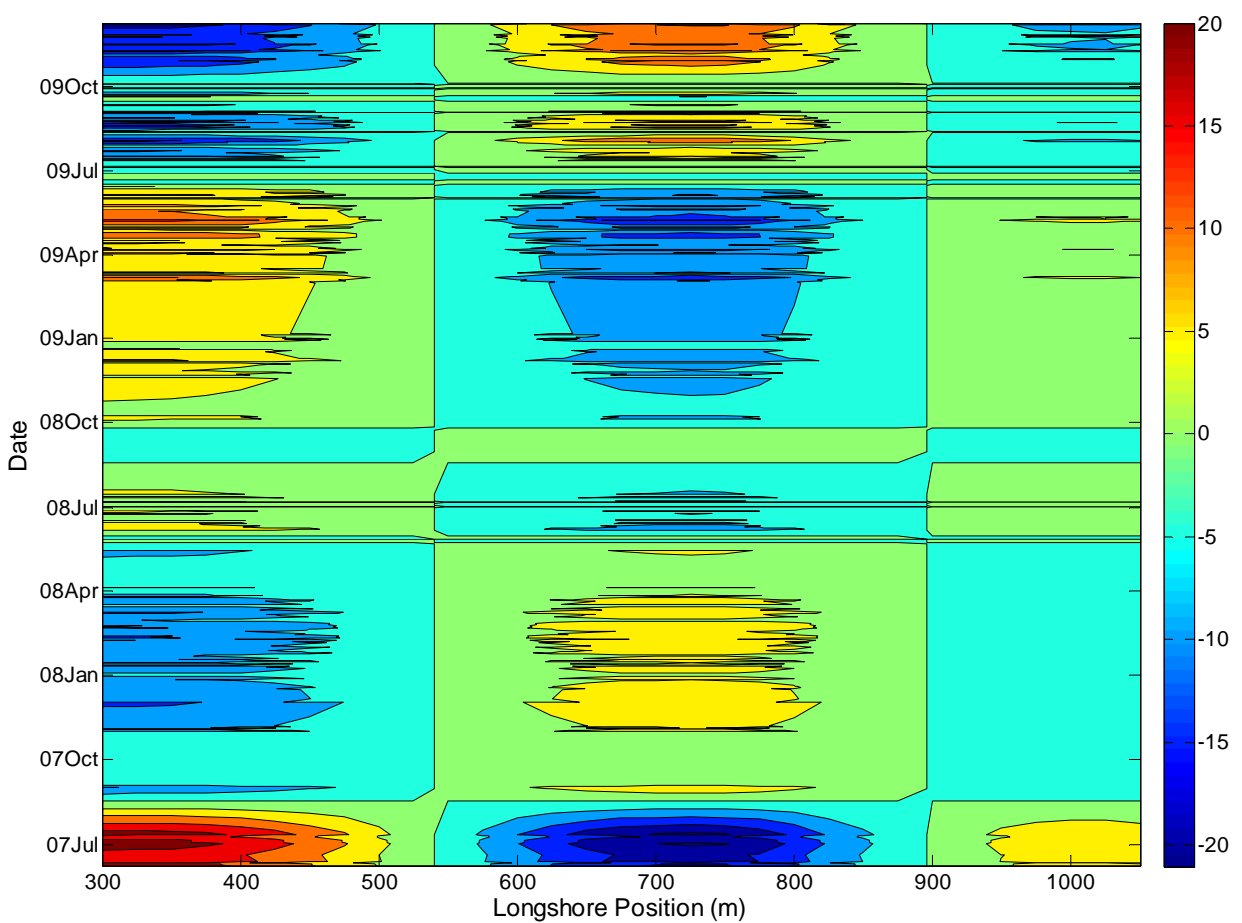

Figure 12. The combined eigenfunction pair, $y_{3}(x, t)$, of the third mode based on the EOF analysis.

\section{DISCUSSIONS}

In this section, a general sand spit morphodynamic scenario is drawn based on the observation and analysis on the field recorded images over the two and half year period. As mentioned previously in Table 1, a large amount of sediment was provided to the river mouth nearshore area owing to the severe river flood accompanying with the typhoon T0704. There was no other such tremendous sand 
supply from the river during the research period. Taking into account the unique sand spit collapse phenomenon occurred in typhoon T0704, a significant extra sand discharge from the Tenryu River was stored in front of the sand spit. Although the apparent recovery of the sand spit accomplished two months later after typhoon T0709 (Liu, et al., 2008), influence owing to the extra sand discharge to the nearshore morphodynamics persists for a much longer duration.

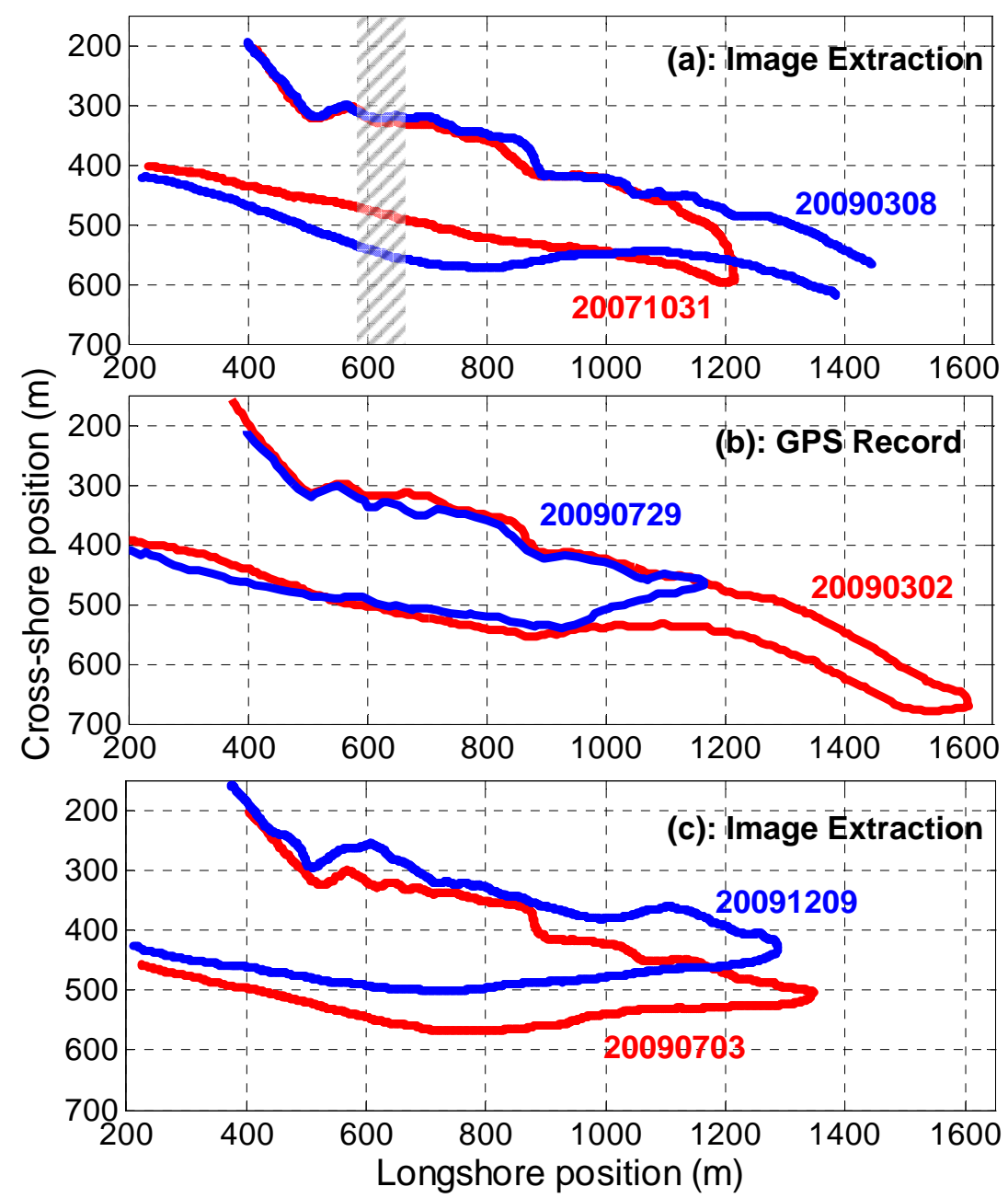

Figure 13. Sand spit profiles recorded at several specified dates during the research period. (a) Imageindicated sand spit profiles on Oct 31, 2007 and Mar 8, 2009. Shadowed area represents the sand spit collapse location in typhoon T0704. (b) GPS-recorded sand spit profiles on Mar 2, 2009 and Jul 29, 2009. (c) Image-indicated sand spit profiles on Jul 3, 2009 and Dec 9, 2009.

Figure 13 illustrates the sand spit profiles recorded at several representative dates during the research period. In Figure 13(a), the sand spit profile extracted from the field image recorded on Oct 31, 2007 represents a typical sand spit situation just after typhoon T0709. In the subsequent period, as revealed from the first mode of EOF analysis, the sand spit migrated seaward along the cross-shore direction which implicates the extra sand supply stored in front of the sand spit after typhoon T0704 was transported back to the shore. Such nearshore sand movement is straightforward since the extra sand storage modified the nearshore bathymetry and also changed the corresponding wave field. At the same time, the eastward longshore transport was prevailing as indicated from the second mode of EOF analysis, which moves sands towards the sand spit tip. Significant eastward extension of the sand spit was observed as shown by the sand spit profile recorded on Mar 8, 2009. Due to the limitation of camera recording azimuth, east end of the sand spit was not fully recorded in the Mar 8, 2009 images. Comparing two sand spit profiles in Figure 13(a), accretion along the cross-shore direction and the eastward longshore transport are confirmed. During the research period, the sand spit profiles were 
also irregularly recorded using the Global Positioning System (GPS), which thoroughly covers the whole sand spit area. Figure 13(b) demonstrates the sand spit profiles recorded from the GPS on Mar 2, 2009 and Jul 29, 2009. Comparing these two profiles, it is easy to know that a certain amount of sands was lost from the east end of the sand spit within this period. These sands may be transported further east or moved to the offshore region under the coactions of waves, river flows and tidal currents. After losing sand from the east, the sand spit morphodynamics were also modified. In the following time period, beach erosion occurred which migrated the sand spit landward, and the westward longshore movement prevailed which rotated the sand spit in an anti-clockwise direction. These are demonstrated in Figure 13(c) which presents the sand spit profiles recorded on Jul 3, 2009 and Dec 9, 2009.

After these analyses, a general picture of the sand spit evolution process within the research period can be proposed that after typhoon T0704, a two and half year asymmetric cycle for sand spit morphodynamics underwent. In which, the sand spit shoreline accretion, together with a eastward longshore transport, was dominant for the first two years. Nevertheless, significant sand loss from the east end of the sand spit occurred around Jun 2009, which changed the relevant nearshore sand movement pattern. Subsequently, significant shoreline erosion, accompanying with a westward longshore transport, became predominant in this area.

\section{CONCLUSIONS}

Long-term monitoring on the sand spit morphodynamics at the Tenryu River mouth was performed based on the sand spit profiles extracted from the field recorded images between Apr 2007 and Dec 2009. Qualitative description on the sand spit evolution process was conducted in terms of the time stack image specified at the representative longshore transection position. To figure out internal insights of the nearshore response, quantitative discussions were carried out through the bulk statistical analysis and the empirical orthogonal function technique.

The riverside morphodynamics reflects a short-term, intensive variation process which is closely related to the extreme events, such as wave overtopping and river flood. During typhoon T0704, sand spit collapsed owing to the intensive river flood which induced significant erosion on the riverside boundary; whereas during typhoons T0709 and T0918, the river side sand spit migrated towards landward due to the sediment movement induced by the wave overtopping.

In case of the seaside morphodynamics, the sand spit shoreline demonstrates a long-term, gradual modification process. Based on the first mode of the EOF analysis, an asymmetric cross-shore movement pattern is confirmed in which a slow shoreline accretion process prevailed from Jun 2007 to Jul 2009, followed by a rapid erosion process in the subsequent several months. Nevertheless, there is no change on the mean shoreline location with respect to the cross-shore movement. The longshore sediment movement feature is mainly characterized through the second mode results of the EOF analysis. The second spatial eigenfunction presents a nodal point at $775 \mathrm{~m}$ longshore location which is the pivot of the shoreline rotation in terms of the longshore movement. Before Jan 2009, eastward longshore transport with a clockwise sand spit rotation is predominant; whereas, westward longshore transport accompanying with an anti-clockwise sand spit rotation is confirmed afterwards. Influence from typhoon events can be identified through the third mode results of the EOF analysis, which also show the increasing longshore variability with a minor degree.

Within the studied two and half year period, the sand spit morphodynamic scenario is proposed. After an extra river flood-induced sediment supply from typhoon T0704, the sand spit underwent an asymmetric cycle. In which, the extra sands stored in front of the sand spit were transported back to the sand spit (shoreline accretion) and moved to the eastward simultaneously (eastward longshore transport). Around Jun 2009, a large amount of sand loss occurred at the east end of the sand spit which modified the nearshore sediment movement pattern. Following it, shoreline erosion, together with a westward longshore transport, became prevailed.

\section{ACKNOWLEDGMENTS}

We would like to thank Dr. T. Takagawa, the University of Tokyo, for his helps during the field survey. This study is a part of Tenryu-Enshunada Project, "Dynamic sediment management and coastal disaster prevention by advanced technologies” supported by the Special Coordination Funds for promoting Science and Technology of Ministry of Education, Culture, Sports, Science and Technology, Japan. 


\section{REFERENCES}

Aarninkhof, S.G.J. 2003. Nearshore bathymetry derived from video imagery. PhD thesis, Delft University of Technology, Delft University Press, Delft, 175 pp.

Aubrey, D.G. 1979. Seasonal patterns of onshore/offshore sediment movement. J. Geophys. Res., 84(C10), 6347-6354.

Fairley I., M. Davidson, K. Kingston, T. Dolphin, and R. Phillips. 2009. Empirical orthogonal function analysis of shoreline changes behind two different designs of detached breakwaters. Coastal Engineering, 56(11-12), 1097-1108.

Hansen, J.E., and P.L. Barnard. 2010. Sub-weekly to interannual variability of a high-energy shoreline. Coastal Engineering, in press.

Holland, K.T., R.A. Holman, T.C. Lippmann, and J. Stanley. 1997. Practical use of video imagery in nearshore oceanographic field studies. IEEE J. of Oceanic Eng., 22(1), 81-92.

Holman, R.A., and J. Stanley. 2007. The history and technical capabilities of Argus. Coastal Engineering, 54(6-7), 477-491.

Larson, M., M. Capobianco, H. Jansen, G. Rozynski, H.N. Soughgate, M. Stive, K.M. Wijnberg, and S. Hulscher. 2003. Analysis and modeling of field data on coastal morphological evolution over yearly and decadal time scales. Part 1: Background and linear techniques. J. of Coastal Research, 19(4), 760-775.

Liu, H., S. Sato, Y. Tajima, G. Huang, and H. Fujiwara. 2007. Investigation on the historical evolution of alluvial deposits along the Tenryu River and the Enshu Coast. Proceedings of the $4^{\text {th }}$ Asian and Pacific Coastal Engineering Conference, Nanjing, China, 1139-1150.

Liu, H., Y. Tajima, and S. Sato. 2008. Field study on the nearshore sediment process around the Tenryu estuary using image analysis, Proceedings of $31^{\text {st }}$ International Conference on Coastal Engineering, Hamburg, Germany, 2064-2076.

Miller J.K., and R.G. Dean. 2007. Shoreline variability via empirical orthogonal function analysis: Part I temporal and spatial characteristics. Coastal Engineering, 54(2), 111-131.

Plant, N.G., S.G.J. Aarninkhof, I.L. Turner, and K.S. Kingston. 2007. The performance of shoreline detection models applied to video imagery. J. of Coastal Research, 23(3), 658-670.

Southgate, H.N., K.M. Wijnberg, M. Larson, M. Capobianco, and H. Jansen. 2003. Analysis of field data of coastal morphological evolution over yearly and decadal timescales. Part 2: Non-linear techniques. J. of Coastal Research, 19(4), 776-789.

Takagawa, T., Y. Tajima, H. Liu, S. Takewaka, and S. Sato. 2011. Dynamic topography changes of sand spit of the Tenryu River mouth due to overtopping waves. Proceedings of Coastal sediments' 11, Miami, Florida, USA, accepted.

Winant, C.D., D.L. Inman, and C.E. Nordstrom. 1975. Description of seasonal beach changes using empirical eigenfunctions. J. Geophys. Res., 80(15), 1979-1986. 